\title{
16 Institutional care for older people in Poland during pandemic
}

\author{
Regulations, practice and \\ thoughts about the future
}

\section{Joanna M. Salachna and Anna Szafranek}

The COVID-19 pandemic revealed systemic imperfections with regard to institutional care in every country, which specifically included, and still includes, care aimed at older adults. This weakness is specifically visible in Polish social care facilities, for older persons and somatically ill people, and in hospices (both in stationary hospice facilities as well as hospice home care). Poland has introduced numerous legal regulations concerning social contacts to limit the spread of COVID-19 infections (i.e. maintaining social distancing, limiting the possibility to travel). These regulations applied and continue to apply to the society in general and lack procedures regulating the realm of institutional care aimed at older adults. Moreover, there is a lack of common standards and suggestions in this aspect. This problem, at least to some extent, results from the fact that the discussed institutions are monitored and/or run by local authorities and alternatively by legal entities. However, there is no single, central organ that would coordinate their activity. Additionally, staff working at the aforementioned institutions could not manage the situation and, in fact, preferred to limit the accessibility and physical contact with the institutions and residents, rather than establish procedures to be followed. Apart from the existing epidemic threat, this situation caused a significant dysfunction of social relations. It turned out that even the closest members of a family could not directly contact their older relatives, as well as provide support with the realisation of vital functions and maintain relationships within a family. This internal closure of facilities also meant the inability to use services of the institutions (for instance, stationary hospice facilities) by people who found themselves in a situation requiring urgent support during the pandemic period. All of the mentioned aspects contributed to the deterioration not only of the quality of institutional care but also the condition (both physical and psychological) of older adults - who take advantage of the 
aforementioned support. This situation has shown that it is imperative to elaborate common standards in care aimed at older adults during a crisis for the future. They could be recognised either as guidelines or in the form of legal regulations. Fundamentals of such standards were proposed in this chapter.

\section{Introduction}

As a result of the spreading COVID-19 epidemic, which consequently led to a pandemic, the system of institutional care for older adults was in 2020 challenged with previously unknown problems both in the local as well as global dimension. The new reality exposed systemic imperfections with regard to institutional care, which particularly affected and continues to affect the care of the older persons. These weaknesses manifested themselves clearly in Polish social care facilities, for older and somatically ill people, and hospices (both in stationary hospice facilities as well as hospice home care). On the one hand, Poland implemented legal regulations concerning social contacts to limit the spread of infections (for instance, maintaining social distancing, wearing face coverings in public spaces or restraining the organisation of certain events - both public as well as family gatherings). However, these legal principles have concerned and apply to the general public (or individual provinces or regions of the country), and at the same time there are no detailed provisions regulating the sphere of institutional care for the older persons. Therefore, the aim of this chapter is to review the current legal and social situation in the field of care for the older adults and to answer the following questions: what should be the standards of institutional care aimed at older persons during a pandemic? Who should establish these standards and what should be the methodology of their development? These questions are significant both from the sociological and legal point of view, but also from the humanistic and public health perspectives.

\section{Socio-legal situation during the COVID-19 pandemic}

General rules for the functioning of entities and institutions, as well as regulations that concern decreasing infection numbers, limiting the spread, preventing and fighting consequences, including those socio-economic of the COVID-19 illnesses, have been stipulated by the Polish parliament. These are included in the parliament's Act in force since the 8th of March 2020 (Act of 2 March 2020). Law of 2nd March 2020 on special arrangements for the prevention and combating of COVID-19, other infectious diseases and crisis situations caused by them -- [hereinafter: u.a.cov.], which by mid-July 2021 had already been amended nearly 60 times. More detailed solutions, 
which aim to limit the spread of the epidemic have been, of course, included in different legal acts. Thus, separate parliamentary acts from the

u.a.cov. regulate the functioning of such aspects in the era of epidemic, e.g., implementation of operational programs co-financed by the European Union, awarding public contracts of particular importance in the indicated period, or rules of support for entrepreneurs. It is worth pointing out that so far, the state bodies (parliament and ministers) have issued around 200 legal acts related to the containment of the pandemic and reduction of its effects, including mainly executive regulations (in the number of 176). These include regulations from the Ministry of Health, Ministry of Family, Labour and Social Policy, Ministry of Education. Currently 87 executive regulations are in effect (Internet System of Legal Acts (ISAP), whereas new bills are still being prepared, which are to enable the efficient functioning of the state and basic institutions as well as society in times of pandemic. In addition, Polish local government units are also authorised to issue locally binding acts in connection with the current state of the epidemic, but to the extent permitted by universally binding acts (issued by state authorities).

In Poland, the state of the epidemic due to SARS-CoV-2 infections is in force (on the basis of the ordinance of the Minister of Health issued under the authorisation included in the u.a.cov.) from 20th March 2020. With such a large number of legal acts, as indicated earlier, to ensure uniformity of treatment in combating and preventing infections and illnesses and the negative effects of COVID-19, it would seem that all the necessary basic issues in this area have been settled within almost six months. Namely, issues related both to the functioning of people in the "ordinary" public sphere (e.g., concerning the principles of movement, distance and basic protection measures) and (most importantly) in the "special" spheres, which include health care in the broad sense, including the older adults and the chronically ill. On the other hand, however, the multitude of various acts directly results in legal overregulation (in the sense of the number of legal acts), which by no means results in the consistency of regulations and does not give clear guidelines on how to deal with specific situations. In most public institutions, such as courts, offices and social care facilities, it is the managers who decide individually on the ways of proceeding in a situation of epidemic threat. In practice, this means duplicating patterns of conduct already established in other institutions. However, without a good recognition of the general state and the specifics of the social and institutional environment and the internal organisation of individual entities, such practice is not a good solution. In such cases there is no situational adequacy of rules and procedures.

Here we decide not to present the basic legal regulations that are in force in Poland in the era of a pandemic, as they do not differ significantly from those introduced in most EU countries (Tello Limanco 2020). However, from the point of view of the subject matter of the study, it is important that neither the generally applicable acts (laws and regulations), nor the internal 
acts issued by the relevant services (in Poland, it is primarily the Chief Sanitary Inspector) have any guidelines concerning the rules of contacts and conduct in institutions that are social care facilities or hospices. The only regulation concerning the indicated facilities refers to the possibility of providing work by the employees of such facilities in a situation when they are under quarantine (Act of 2 March 2020, art. 4e u.a.cov.) - if the persons under care agree to it. Therefore, we are dealing with a situation in which the infected personnel can continue to work. In fact, the question of whether or not the residents have consented to this practice is partly illusory (if they do not consent, the residents will be at least partially deprived of care). There are no guidelines as to whether the work of the staff is subject to the consent of all or part of the residents. In addition, the question also arises against the background of the above regulations: is it only the resident who would give their consent individually "under the care" of quarantined staff? There should be no place for such a discussion in times of pandemics or epidemics. Even if the general act leaves certain issues unregulated (it can be assumed that it is deliberately to secure flexibility in individual situations), it should force specific issues to be regulated by the local, central or facility management. Of course, it would be possible - by analogy - to assume that in recognised institutions the regulations and guidelines addressed to typical health care institutions (primarily hospitals) should be applied. Such an assumption, however "convenient" for the staff or managers, is without any factual justification, as other objectives are pursued by typical health care institutions and others by social care facilities and hospices. This in turn is implied by a number of other factors, namely the purpose of the institution and the duration of the guest/patient's stay determine the emergence of a different type of social relationship between the staff and the guests and between the staff and the families of the guest/patients. It is also important to note that the living, psychological and social needs of the guests and their families are different. These considerations argue for the need to develop a methodology for the development of rules of conduct in nursing homes and hospices in relation to epidemic risks and universal recommendations in this area.

\section{Legal basis for the functioning social care facilities in Poland}

In the Polish system of state law there are several entities managing social care facilities (municipal and supra-municipal), which at the same time determines and influences not only the determination of standards (also in the scope of dealing with crisis situations) but also clearly indicates who has the right to set those standards. Local government units (territorial selfgovernment units) are responsible for organising social welfare, among others in the form of running and providing places in social care facilities, and they may cooperate with churches or associations in carrying out this task (Act of 12 March 2004 on social assistance; art. 2 sec. 2 in connection with 
art. $17 \mathrm{sec} .2$ of the Act of 12 March 2004 on social welfare - hereinafter: u.p.s.). Thus, the functioning of the social care facilities is possible at the municipal, district and self-government voivodeships level (Act of 12 March 2004 on social assistance; art. 17 par. 1 u.p.s.; art. 19 pt. 10 u.p.s.; art. 21 pt. 5 u.p.s.). It is the duty of municipalities to provide their residents in need of care with a place in stationary institutions, while institutions of a supra-municipal nature take in the residents regardless of their place of residence (Act of 12 March 2004 on social assistance; art. 17.1 .16 u.p.s.; art. 19.10 u.p.s.).

Stationary social care facilities [2; art. 54-56 u.p.s.] are the basic and most important institutions offering support to people who, due to their age or health condition, are unable to function independently and require 24-hour care. It should be noted that in accordance with the regulations in force (Act of 12 March 2004 on social assistance; art. 56 sec. 2 u.p.s.) persons in need are, as a rule, directed to an institution located as close as possible to their place of residence, which is connected with ensuring the sense of safety of the residents, not detaching them from the current environment and maintaining social relations, which in many cases they built throughout their lives.

The basic duties of social care facilities (Act of 12 March 2004 on social assistance; Art. 55, par. 1-2 u.p.s) are to provide residential, nursing, supportive and educational services at the level of the current standard, in the scope and forms resulting from individual needs, with the organisation of the facility, as well as the scope and level of its services taking into account the freedom, intimacy, dignity and sense of security of the residents. The current pandemic situation, as well as the temporary closure of the facilities applied by the authorities, allow us to assume that the above-mentioned assumptions were not fulfilled. It should be remembered that the state of health (especially the mental condition) of an older persons living in an institutional environment is largely dependent on relations with the family and maintenance of regular social contacts. In a situation where meetings with loved ones are limited or completely impossible, the sense of security of the residents may be compromised, which in turn leads to emotional problems and even psychosomatic symptoms. The pandemic has also caused a situation of social isolation, increasing not only loneliness, but above all a sense of alienation, which has a negative impact on mental health (Hossein Javadi \& Nateghi 2020: 1). That is why it is so important to properly prepare social care facilities to function efficiently in any situation (including epidemics).

In accordance with Article 57, paragraph 1 of the u.p.s. (Act of 12 March 2004 on social assistance), social care facilities (with the prior consent of the voivode) may be run by: local government units, the Catholic Church, other churches, religious associations and social organisations, foundations and associations, other legal entities and individuals. In connection with the designated entities authorised to run the social care facilities, a distinction is made between public (run by local government units) and non-public (in accordance with the u.p.s., these are institutions supporting authorities, cooperating with them on a partnership basis) (Sierpowska 2014: 37, 295). 
One of the key documents (apart from the Act on Social Welfare, social care facilities regulations, statutes and plans of individual needs of the residents) affecting the proper functioning of the discussed institutions is also the organisational regulations, developed by the management of a given social care facility. In accordance with $\S 4$ of the Ordinance of the Minister of Labour and Social Policy of August 23, 2012 (Regulation of the Minister of Labour and Social Policy of August 23rd, 2012 on social welfare homes), it must be adopted by the executive body of the local government unit, i.e., the head of the municipality council, the mayor or the president. In the case of a community house, and if the owner of the house is a non-public entity, the organisational regulations are established by that entity.

It should also be mentioned that the individual DPSs function on the basis of plans of individual needs of the residents, and these plans should be developed (assuming that the health of the resident allows for it and the client expresses willingness to participate in creating such a plan) together with the residents. Considering the current social situation, it seems reasonable to re-examine the existing plans and adjust them to the new legal and social requirements related to the Covid-19 epidemic.

\section{Social care facilities in Poland - the actual situation}

To thoroughly analyse the lack of standards for the functioning of social care facilities during an epidemic, it was imperative to establish the number of such institutions, which at the same time outlined the number of older adults and/or chronically, somatically ill people that are under these facilities' care. Table 16.1 presents the number of places in public and non-public social care facilities in Poland, including three particular voivodeships (as at 31st December 2019). From all of the cases, institutions designed specifically for older adults and/or somatically ill people were distinguished.

It has been considered reasonable to compare how stationary facilities (both public and non-public) in particular voivodeships responded to the epidemiological situation and if they induced (if so, under what conditions) any guidelines with regard to the functioning of social care facilities. While deciding upon the voivodeships to analyse, authors followed the contractual division of Poland into three parts: Poland A, B and C, which are classified according to their level of social and economic development, including the transport network, industry and culture, among others. Every chosen voivodeship will be represented by its municipalities, although considering a very specific socio-economic character of Masovian voivodeship (the most developed region, centre of the country, the smallest indigenous population, capital city), it was not taken into account. Additional criteria of choosing voivodeships were: the amount of social benefits paid and municipalities' expenditure on social welfare. As of such, Poland A will be represented by local government units of the Greater Poland Voivodeship, which can be characterised with the highest expenditure (apart from Masovian 
Voivodeship) on social welfare. Poland B will be represented by Podlaskie Voivodeship characterised with the lowest expenditure on social welfare. Poland C will be represented by Lubusz Voivodeship with one of the lowest amounts of social benefits paid (after Opolskie Voivodeship). Moreover, municipalities in Lubusz Voivodeship have the lowest incomes in the country. While assessing the criteria, current data from the Central Statistical Office were consulted (Central Statistical Office 2019: 466-468).

The analysis of data from Table 16.1 indicates how many people in need of help are impacted by the issue of lack of standards/guidelines concerning the functioning of social care facilities in the light of the pandemic, as chronically, somatically ill and/or older adults constitute $36.79 \%$ of all the resident of such facilities. Moreover, both in Greater Poland and Podlaskie Voivodeships nearly half of social care facilities are allocated to chronically somatically ill and/or older adults (older persons account for $39.78 \%$ and $40.97 \%$ of all the residents of these facilities, respectively). In Lubusz Voivodeship, this percentage is slightly lower $(21.30 \%)$, which is nonetheless a significant group.

With the aim of supplementation and review of implemented guidelines, or their absence, in relation to the epidemiological situation, an analysis of randomly chosen websites of social care facilities in the discussed voivodeships was conducted (Table 16.2). It is important to note that the methodology of choosing particular institutions was simplified, the conducted analysis is a pilot study (the sample should not be treated as representative) and presented conclusions are demonstrative. These conclusions most importantly aim to facilitate the development of guidelines on the standards of social care facilities' functioning during the epidemic, but also to simplify establishing methodology to develop such guidelines. In each voivodeship four websites were analysed (initially, two websites were supposed to represent public institutions whereas the other two non-public facilities, located in urban as well as rural areas). However, choosing such a sample was only possible in Greater Poland voivodeship (no non-public facilities function in Lubusz voivodeship, while in Podlaskie voivodeship there is only one non-public social care facility). As a result, in the two remaining voivodeships the analysis was focused primarily on websites of public institutions managed by local governments.

Data presented in the above Table 16.2 indicate misinformation (websites of half of the analysed institutions, i.e., 6 among 12 social care facilities, lack information on their functioning during a pandemic) and the absence of not only specific, but more importantly relatively standardised guidelines on rules for the organisation of social care facilities. It is characteristic that none of the analysed non-public facilities included any information on their functioning during a pandemic while guidelines in the majority of institutions were limited to a statement: "No visitors until further notice". Only two facilities allowed visits, yet one of them limited the possibility to circumstances in which direct contact is absolutely required (voivodeship 
Table 16.1 Number of places and residents in social care facilities (as at 31st December 2020)

Public Non-

facilities public

facilities

Poland in general

Registered social care facilities in total

Number of places in total

Number of residents in total

Including: registered social care facilities for chronically, somatically ill people and/or older adults

Including: number of places in social care facilities for chronically, somatically ill people and/or older adults

Including: number of residents in social care facilities for chronically, somatically ill people and/or older adults

Poland A: greater Poland Voivodeship

Registered social care facilities in total

Number of places in total

Number of residents in total

Including: registered social care facilities for chronically, somatically ill people and/or older adults

Including: number of places in social care facilities for chronically, somatically ill people and/or older adults

Including: number of residents in social care facilities for chronically, somatically ill people and/or older adults

Poland B: Podlaskie Voivodeship

Registered social care facilities in total

Number of places in total

Number of residents in total

Including: registered social care facilities for chronically, somatically-ill people and/or older adults

Including: number of places in social care facilities for chronically, somatically-ill people and/or older adults

Including: number of residents in social care facilities for chronically, somatically-ill people and/or older adults

Poland C: Lubusz Voivodeship

Registered social care facilities in total

Number of places in total

62

6,375

5,901

26

2,233

1,950

$826 \quad 605$

$81,004 \quad 66,223$

$75,133 \quad 61,356$

266

221

14,781

13,777

351

$30,134 \quad 25,026$

5,108

$26,563 \quad 22,094$

4,469

85

\section{4,469}

$\begin{array}{ll}51 & 11 \\ 5,329 & 1,046 \\ 4,967 & 943 \\ 22 & 4\end{array}$

4

$\begin{array}{lll}21 & 15 & 6 \\ 2,337 & 1,876 & 461 \\ 2,209 & 1,767 & 442 \\ 10 & 9 & 1\end{array}$

$956 \quad 931 \quad 25$

$864 \quad 844 \quad 20$

Number of residents in total

Including: registered social care facilities for chronically, somatically ill people and/or older adults

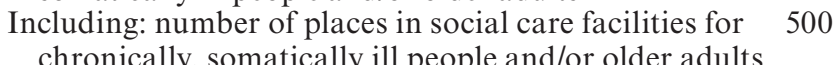

Including: number of residents in social care facilities for 396

$\begin{array}{lll}23 & 21 & 2 \\ 2,337 & 2,225 & 112 \\ 2,113 & 2,001 & 112 \\ 5 & 5 & 0 \\ 500 & 500 & 0 \\ 396 & 396 & 0\end{array}$
chronically, somatically-ill people and/or older adults

Source: own work based on: Reports on facilities providing care and support, Ministry of Family, Labour and Social Policy, accessible online: https://www.gov.pl/web/rodzina/statystyka-za-2020 [access date: 16.07.2021] 
Table 16.2 Examples of social care facilities for older adults and/or chronically somatically ill people with guidelines implemented as a result of COVID-19

Type of a social care facility Guidelines and its location

Poland A: greater Poland Voivodeship

Non-public social care No guidelines facility (rural municipality)

Non-public social care No guidelines facility (rural municipality)

Public social care facility Visits in the facility are possible every day from 10 a.m. (rural municipality)

Public social care facility No guidelines to 12 a.m. and from 2 p.m. to 5 p.m., however it is forbidden to move freely around the facility without reporting it to staff.

Additional guidelines:

- To enter the facility, visitors are required to notify office no. 2 by ringing a bell and wait for a member of staff to come,

- One resident can be visited by the maximum of two people that are required to wear face masks,

- Before entering the facility, visitors' temperature will be checked by a staff member and they will be required to use a hand sanitiser as advised by staff,

- Information about a visit will be noted in a visitors' registry.

(urban municipality)

Poland B: Podlaskie Voivodeship

Public social care facility (urban municipality)

Public social care facility (urban municipality)

Public social care facility (rural municipality)

Non-public social care facility (rural municipality)

Poland C: Lubusz Voivodeship

Public social care facility (rural municipality)

Public social care facility (rural-urban municipality)

Public social care facility (rural-urban municipality)

Public social care facility (rural municipality)
- No visitors until further notice,

- Restrained activity of residents outside of the facility; only necessary activities allowed (until further notice).

- No visitors until further notice.

- No visitors until further notice.

No guidelines

No guidelines

- No visitors until further notice; if physical contact with a resident is absolutely required, visits will be allowed only after arranging appropriate conditions with the facility's manager or their deputy,

- No visitors until further notice.

No guidelines 
in Poland C) whereas the other one (voivodeship in Poland A) permits visits and their procedure was described in detail. Data suggest that stricter guidelines (mainly limiting the possibility to visit residents) are followed in social care facilities located in urban municipalities (which probably results from greater population density, population in general and more visitors) while in some rural-urban and rural municipalities guidelines allowed visits that follow the sanitary regime. As such, it appears legitimate for all institutions to be obliged to update their websites, whereas in the current epidemiological situation not only to establish guidelines on a regular basis, but also make the information available to the public (on their websites). At the same time, methodology for establishing guidelines should be uniform in the whole country to prevent residents from feeling injustice, when different institutions' organisation and functioning are contradictory (for instance, a complete ban on any visits and the possibility to visit resident while following the sanitary regime).

Another issue, that should have been resolved at the beginning of the pandemic, was the insufficient number of staff in social care facilities, which was caused by the staff's infections with COVID-19 or/and their mandatory quarantine. Poland has recorded numerous, vocal in the media, examples of support offered to residents and staff of social care facilities by volunteers, nuns or other social services. It is important to note that the deficits in staff concern not only its quantity, but also the workers' insufficient professional competence, or its complete lack (i.e. when a social worker is required to pursue responsibilities of a nurse). A study conducted in the US among 161 workers at social care facilities showed that they performed many activities outside of their competence, for instance, physiotherapists performed simple medical tasks in addition to washing and feeding residents. Another challenge was posed by relocating residents to different rooms (in the case of people who had to undergo quarantine) since the majority of residents had been occupying their rooms for years and as a result of quarantine their personal belongings had to be moved (to maintain the feeling of safety) (Seshadri et al. 2020).

Unclear guidelines on accepting new residents in stationary social care facilities cause other difficulties. In Poland, during a period of temporary closure of social care facilities and hospices, accepting new residents was halted. Such a situation should not have occurred since families, which could not care for, or continue to care for, a terminally ill older adult were deprived of the possibility of institutional support, i.e. a place in a stationary hospice. On the other hand, a potential acceptance into a stationary facility would most probably make visiting a patient impossible, which both from a perspective of a dying person and their family should not occur. For instance, in one of the German states, North Rhine-Westphalia, admitting new patients was not limited at all (however, every new patient was subjected to a 14-day quarantine). As a result of housing conditions, the situation of German residents of social care facilities is significantly better than the Polish ones (which is especially important during the pandemic) as the majority of facilities located in particular German states offer single rooms (although double rooms are occasionally offered as well) (Dichter et 
al. 2020). On the contrary, Polish social care institutions single rooms are rarely occupied with the majority of room offered being double, triple or even quadruple rooms, which hinders everyday functioning of residents and staff considerably during the pandemic.

\section{Diagnosis of the problem and recommendations}

In the case of the discussed institutions, there are two basic problems the lack of general guidelines on the functioning of social care facilities and actual closures of such facilities (refusing to accept new residents and excluding residents from contact with the outside environment). Yet the most serious issue appears to be the lack of clear and general guidelines for all social care facilities and hospices. However, considering methodological aspects relating to the type and the changing scale of the threat, that statement is not entirely true. This claim is justified by the variability of the risk in itself, as well as its severity in the country or a region, etc., as well as the specificity of the facility (type of facility, i.e. social care facility/hospice, number of residents, their health condition, location of the facility, number of staff, infrastructure). Hence, authors assumed that the methodology of constructing guidelines must at its base take place at two levels, i.e., nationwide/central and at the individual/given facility's level. Of course, this approach can be accused of a mistake in locating the decision-making centre. For it can be indicated that local authorities have better overview of the situation in a given territory. However, such approach is not correct due to the fact that the authorities at the central level have:

- on the one hand, general data, i.e., data on the situation in the country as a whole,

- on the other hand, analytical data of individual regions relativising their situation, which in turn provides the basis for the development of a nationwide specific map in terms of the threat, intensity and course of the epidemic. In addition, the methodological correctness requires including determinants of an intra-organisational resource nature, i.e. about staff and the use of the facility's infrastructure.

The presented assumptions indicate that guidelines in the discussed subject must consist of two basic elements: general and detailed (individual), while nationwide guidelines (level I) must be created initially. This is because of their fundamental importance and the nature of the data that the central government has at its disposal (as already mentioned). Individual /particular facility's guidelines (level II) should, in turn, regulate two areas/dimensions: intra-organisational (level IIA) and relations with the environment (level IIB). In the individual scope, the intra-organisational rules should be developed first. Intra-organisational rules such as: (1) appropriate training 
of employees (following rules in interpersonal contacts, using equipment, preparing food), which is, in fact, the manner of providing care; (2) the possibilities of using infrastructure (medical and/or rehabilitation equipment, size of rooms, number of toilets) imply maintaining a certain level of safety in a given facility. This level, in turn, is important in determining whether at all and what degree of contact with the outside environment may take place under given circumstances and the facility's conditions.

Considering the dynamics of the epidemic (and epidemics, in general), it is impossible to define guidelines of a general or individual nature in advance. However, it is possible to demonstrate (in the form of guidelines) recommendations as to what these guidelines should not be and/or what provisions they should contain. In this regard, of course, some preliminary assumptions are needed regarding the specificity of the functioning of social care facilities, as well as hospices. The two main assumptions are:

- the need to maintain social relations between the residents of social care facilities (or hospices) as a necessary condition to maintain the proper psychophysical condition of the residents and their family members;

- the need to ensure the functioning of social care facilities and hospices, including providing care to existing residents and accepting new ones.

\section{For further discussion...}

Taking into account the aforementioned assumptions, in the light of previous analysis, it is reasonable to take into account the following principles in the guidelines:

- Temporary closure of social care facilities (limiting contacts with the outside environment to the necessary minimum) cannot mean that the admission of new residents is excluded (which actually occurred in Poland). This claim applies to both nursing homes and residential hospices. The refusal to admit new residents may be treated (in the case of public institutions) not only as a failure to fulfil the tasks imposed on them, but also as actions discriminating against persons who are formally entitled to such care.

- Residents/patients must not be completely deprived of contact with the outside environment. In this respect, a distinction must be made between the resident and their closest relatives (family members or friends) and between the resident and the environment "at large" (e.g. going out to the store, going for a walk). In the former, it is possible to limit the number of people the resident may have contact with, provided that the necessary sanitary requirements are maintained. As far as the latter scope is concerned, in justified cases, it can be suspended entirely - but only temporarily and these restrictions should be consistent with the general social restrictions (the are in force nationally or locally). 
- While the above recommendations are of a substantive nature, one cannot underestimate a guideline of an instrumental nature, i.e., without which it is impossible to plan and implement any guideline correctly. This principle is articulated below.

- It is necessary to introduce general principles of preparing the staff of the facilities in terms of procedures for dealing with a state of epidemic/pandemic, as well as to define the principles of organisation of replacement staff (i.e. people replacing employees excluded from the possibility of working, for instance, due to quarantine). It should be noted, however, that the scope of training should be different for the staff (employees) and different for the management of the facilities. The introduction of top-down rules in this aspect results in the uniformity of the application of procedures and the relatively efficient functioning of the whole care system on a national scale, and at the same time excludes the possibility of overinterpretation in the application of procedures. It also gives the necessary flexibility, i.e., making decisions within a generally defined framework. The training of employees is essential in order to maintain uniform safety standards. It should be emphasised that it is imperative to regulate the rules of behaviour of people working in different entities (including social care facilities), especially medical personnel. It is crucial to determine the rules of replacing employees who cannot perform contractual services. To consider in the latter case is the use of staff (e.g. medical) from primary health care institutions, which during the epidemic are mainly focused on giving medical advice on the phone.

Finally, it is important to note that the established guidelines should be: public (socially accessible); - there is a need to publish both Level I (national guidelines) and Level II (individual facility's) guidelines, which is generally not implemented. The development of the first-level guidelines by central authorities with the participation of a wide range of recognised experts (in the field of medical science, in particular) and practitioners is important for the social acceptability of the guidelines. This body should be known to the public, as should the voting results of this body concerning individual guidelines or groups of guidelines.

\section{References}

Central Statistical Office, Statistical Yearbook of Voivodeships, Warsaw 2019.

Dichter M.N., Sander M., Seismann-Petersen S., Köpke S., COVID-19: it is time to balance infection management and person-centered care to maintain mental health of people living in German nursing homes, "International Psychogeriatrics”, Cambridge University Press: 12 May 2020, p. 1-4. DOI: 10.1017/ S1041610220000897. 
Hossein Javadi S.M., Nateghi N., Covid-19 and it's psychological effects on the elderly population, "Disaster Medicine and Public Health Preparedness", Cambridge University Press: 15 July 2020, p. 1-2. DOI: 10.1017/dmp.2020.245.

Internet System of Legal Acts, https://isap.sejm.gov.pl/ [access date: 18.08.2020].

Rozporządzenie Ministra Pracy i Polityki Społecznej z dnia 23 sierpnia 2012 r. w sprawie domów pomocy społecznej (Dz. U. 2018 poz. 734) / Regulation of the Minister of Labour and Social Policy of August 23rd, 2012 on social welfare homes (Journal of Laws of the Republic of Poland 2018, item 734).

Seshadri S., Concannon C., Woods J.A., McCullough K., "It's like Fighting a War with Rocks:" Nursing Home Healthcare Workers' Experiences During COVID-19", "Infection Control \& Hospital Epidemiology", Cambridge University Press: 05 August 2020, p. 1-7. DOI: 10.1017/ice.2020.393.

Sierpowska I., Pomoc społeczna. Komentarz, Wolters Kluwer, Warszawa 2014.

Sprawozdanie o placówkach zapewniających całodobową opiekę i wsparcie, Ministerstwo Rodziny, Pracy i Polityki Społecznej, accessible online: https://www.gov. pl/web/rodzina/statystyka-za-2020 [access date: 16.07.2021].

Tello Limaco I.J., Prawa podstawowe w czasie pandemii COVID-19 w Hiszpanii, "Prawo i Praktyka" Temidnium: June 2020, p. 47-48.

Ustawa z dnia 2 marca 2020 r. o szczególnych rozwiązaniach związanych z zapobieganiem, przeciwdziałaniem i zwalczaniem COVID-19, innych chorób zakaźnych oraz wywołanych nimi sytuacji kryzysowych (Dz. U. 2020 poz. 374 ze zm.) / Act of 2 March 2020 on special solutions related to the prevention, prevention and combating of COVID-19, other infectious diseases and crisis situations caused by them (Journal of Laws of the Republic of Poland 2020, item 374 as amended).

Ustawa z dnia 12 marca 2004 r. o pomocy społecznej (Dz. U. 2019 poz. 1507 ze zm.) / Act of 12 March 2004 on social assistance (Journal of Laws of the Republic of Poland 2019, item 1507 as amended). 